\title{
Hypomethylation of CTCFL promoters as a noninvasive biomarker in plasma from patients with hepatocellular carcinoma
}

\author{
M. M. CHEN ${ }^{1}$, R. C. ZHAO ${ }^{2}$, K. F. CHEN ${ }^{2}$, Y. HUANG ${ }^{1}$, Z. J. LIU', Y. G. WEI ${ }^{2}$, Y. JIAN ${ }^{3}$, A. M. SUN ${ }^{4}$, L. QIN ${ }^{1}$, B. LI ${ }^{2, *}$, Y. QIN ${ }^{1, *}$ \\ ${ }^{1}$ Department of Biochemistry and Molecular Biology, West China School of Basic Medical Sciences and Forensic Medicine, Sichuan University, \\ Chengdu, Sichuan, China; ${ }^{2}$ Department of Liver Surgery, Center of Liver Transplantation, West China Hospital, Sichuan University, Chengdu, \\ Sichuan, China; ${ }^{3}$ Digestive System Department, Chengdu Second People's Hospital, Chengdu, Sichuan, China; ${ }^{4}$ Analytical and Testing Center, \\ Sichuan University, Chengdu, Sichuan, China
}

*Correspondence: qinyang@scu.edu.cn; cdhxlibo@126.com

Received August 19, 2019 / Accepted November 26, 2019

\begin{abstract}
Hepatocellular carcinoma (HCC) is the third deadliest cancer in the world with high morbidity and poor prognosis. CTCFL (CCCTC-binding factor like) is a member of the cancer testis antigen (CTA) family with oncogenic properties. To demonstrate whether the hypomethylation of CTCFL promoters in plasma could be used as a noninvasive biomarker to predict poor prognosis of HCC, we extracted cell-free DNA from the plasma and detected the methylation status of CTCFL in 43 HCC, 5 liver cirrhosis and 6 benign lesion samples using methylation specific PCR (MSP). Our study indicated that the hypomethylation of CTCFL promoters in HCC plasma samples (60.4\%) was significantly different from that in benign lesion plasma samples (16.7\%) with a p-value of 0.043. Analysis of clinicopathological data showed that the methylation status of CTCFL promoters was significantly correlated with microvascular involvement (MVI) $(\mathrm{p}=0.001)$ and postoperative recurrence ( $\mathrm{p}=0.031$ ). Furthermore, clinical prognosis data of 347 HCC patients from The Cancer Genome Atlas (TCGA) database displayed that the hypomethylated group had worse overall survival than the hypermethylated group ( $p=0.0056)$. In conclusion, we provide evidence that the hypomethylation of CTCFL promoters in cell-free DNA is a biomarker for monitoring HCC patients, which can be used as a noninvasive prediction index for tumor recurrence and provide the individualized decision-making for clinicians.
\end{abstract}

Key words: hepatocellular carcinoma, hypomethylation, liquid biopsy, biomarker, recurrence, prognosis

Liver cancer, predominantly hepatocellular carcinoma (HCC), is the third leading cause of cancer death worldwide [1]. Complex etiological factors attribute to the occurrence of liver cancer, such as chronic hepatitis $B$ and $C$ virus (HBV/ $\mathrm{HCV}$ ) infections, alcohol abuse, diabetes, obesity, and some metabolic diseases [2, 3]. Genetic and epigenetic alterations induced by these risk factors play a significant role in the carcinogenesis of hepatocellular carcinoma [4]. Treatments including surgical resection, transplantation, ablation, transarterial chemoembolization, and tyrosine-kinase inhibitors are proven to have survival benefits for HCC patients. Although major progress has been made in the prevention, detection, diagnosis, and treatment of HCC, its prognosis remains poor [5]. Hence, it is urgent to investigate noninvasive biomarkers for monitoring HCC patients.

Recently, liquid biopsies, including the detection of circulating tumor cells, cell-free nucleic acids, and extracellular vesicles, are gradually being implemented in cancer patients [6]. Cell-free DNA (cfDNA) is a small fragment that can be detected in plasma, and the concentration of cfDNA in individuals with cancer can be 50 times higher than normal [7]. Tumor-related genetic and epigenetic alterations, which include single nucleotide mutations, copy number aberrations, and aberrant methylation, have been detected in cfDNA of cancer patients and are associated with tumor burden and malignant progression $[8,9]$. Aberrations in DNA methylation, such as hypermethylation of tumor suppressor genes in cfDNA, have been shown as a powerful prognostic factor [10].

Global DNA hypomethylation occurs in most types of cancer [11]. DNA hypomethylation in tumors is accompanied by abnormal activation of "cancer-testis" genes, which contribute to the key process of tumorigenesis and exhibit carcinogenic characteristics [12]. BORIS (Brother of the Regulator of Imprinted Sites), also called CTCFL (CCCTCbinding factor like), is identified as a paralog of CTCF (CCCTC-binding factor) [13]. CTCFL is one of the cancer testis antigen (CTA) family with 11 zinc finger DNA-binding domains [14], and it is predominantly expressed in 
spermatocytes during early male germline development. On the contrary, CTCFL is barely expressed in normal tissues other than the testis $[15,16]$. But the situation is different in tissues following neoplastic transformation. It's worth noting that CTCFL is abnormally expressed in many primary tumors and cancer cell lines [17-20]. Studies have shown that CTCFL can promote the development, invasion, and metastasis of tumors [21-24]. In addition, epigenetic alterations of CTCFL are considered to be of great value, and the activity of CTCFL promoters is thought to be chiefly regulated by DNA methylation $[25,26]$. Hypomethylation of CTCFL promoters results in the universal expression of CTCFL in endometrial cancer, gastric cancer, and hepatocellular carcinoma, which is highly correlated with clinical stage and prognosis [27-29].

To determine whether CTCFL could be used as a biomarker for liquid biopsies of HCC patients, we extracted cfDNA from the plasma of 76 patients and detected the methylation status of CTCFL promoters. Moreover, we analyzed the correlation between hypomethylation of CTCFL promoters and clinicopathological characteristics. Finally, TCGA data were used to analyze the relationship between methylation and prognosis.

\section{Patients and methods}

Cell culture. K562 cells (purchased from the cell bank of the Chinese Academy of Sciences) were cultured in RPMI-1640 media (HyClone, USA), supplemented with 10\% fetal bovine serum (Gibco, USA), 100 units $/ \mathrm{ml}$ penicillin and $100 \mathrm{micrograms} / \mathrm{ml}$ streptomycin. Cells were grown at $37^{\circ} \mathrm{C}$ in a humidified atmosphere of $5 \% \mathrm{CO}_{2}$.

Plasma samples and normal liver tissues. Normal liver tissues (accidental death) and 76 plasma samples were obtained from the West China Hospital of Sichuan University. All plasma samples were stored at $-20^{\circ} \mathrm{C}$, and consisted of 43 HCC, 19 liver cirrhosis, and 14 benign lesion plasma samples.

DNA extraction and bisulfite conversion. The genomic DNA was extracted from plasma samples with the Axy Prep Body Fluid Viral DNA/RNA Miniprep Kit (Axy Prep, China). And the genomic DNA from cells and tissues was extracted by using the TIAN amp Genomic DNA Kit (TIANGEN, China). Complete bisulfite conversion of GC-rich DNA was performed by using the EZ DNA Methylation-Gold ${ }^{\text {mi }}$ Kit (Zymo Research, USA).

Methylation specific PCR (MSP). We used nested PCR to examine the methylation status in the CpG island of CTCFL promoters. The primers were used previously [17]. Primer sequences of the first round of PCR: forward 5'-GTGTTTTTTTTGGGGTTTTTTTTAT-3' and reverse 5'-CCCAAAACAACCCATACTCTTAA-3'; and the following thermal cycle conditions: $95^{\circ} \mathrm{C}$ for $6 \mathrm{~min}$; $\left(95^{\circ} \mathrm{C}\right.$ for $45 \mathrm{~s}, 56^{\circ} \mathrm{C}$ for $30 \mathrm{~s}$ and $72^{\circ} \mathrm{C}$ for $\left.45 \mathrm{~s}\right) \times 36$ cycles; $72^{\circ} \mathrm{C}$ for $6 \mathrm{~min}$ [28]. Primer sequences of the second round of PCR (MSP): unmethylated forward 5'-GTGTATTGTTATTTTTTATTTTTGTGTTAGTTT-3' and unmethylated reverse
5'-ACСССТCACСACAAAAAACATAACCAA-3'; methylated forward 5'-GTATTGTTATTTTTTATTTTCGCGTTAGTTC-3' and methylated reverse 5'-CCCTCACCGCGAAAAACGTAACCGA-3'. The methylation status was detected by touchdown PCR. The thermal cycle conditions of MSP as follows: $95^{\circ} \mathrm{C}$ for $6 \mathrm{~min}$; $\left(95^{\circ} \mathrm{C}\right.$ for $30 \mathrm{~s}, 66^{\circ} \mathrm{C}$ for $30 \mathrm{~s}$ and decreasing progressively by $1^{\circ} \mathrm{C}$ per cycle, $72^{\circ} \mathrm{C}$ for $30 \mathrm{~s}) \times 8$ cycles; $\left(95^{\circ} \mathrm{C}\right.$ for $30 \mathrm{~s}, 58^{\circ} \mathrm{C}$ for $30 \mathrm{~s}$, and $72^{\circ} \mathrm{C}$ for $30 \mathrm{~s}) \times 32$ cycles; $72^{\circ} \mathrm{C}$ for $6 \mathrm{~min}$.

DNA polyacrylamide gel electrophoresis and silver staining. PCR-amplified products were analyzed by the polyacrylamide gel electrophoresis. The $12 \%$ polyacrylamide gel was pre-run for 30 minutes at a constant $80 \mathrm{~V}$ in the $1^{\prime} \mathrm{TBE}$ buffer, then the gel was run for 2.5 hours with samples. After electrophoresis, the $1 \% \mathrm{AgNO}_{3}$ solution was added to a plastic box containing the gel and the box was shaken for 15 minutes. Then the polyacrylamide gel was washed twice with $\mathrm{ddH}_{2} \mathrm{O}$, each time for 3 minutes. Finally, the developer was added, and the reaction was terminated when a clear band appeared. All of the solutions were prepared before use.

Bioinformatics analysis and statistical analysis. We utilized an interactive database (Disease Meth, http:// bioinfo.hrbmu.edu.cn/diseasemeth/) that offered calculated methylation value of genes in human cancers [30]. Then we obtained prognostic information from The Cancer Genome Atlas (TCGA, USA) and performed Kaplan-Meier analysis to investigate overall survival (OS). Original methylation data and clinical data derived from TCGA.

To assess the correlation between the methylation status and clinicopathological characteristics, SPSS19.0 was installed. We performed the $\chi^{2}$ test, Fisher's exact test, and $\chi^{2}$ test for continuity correction. For all statistical data, $\mathrm{p}<0.05$ was statistically significant.

\section{Results}

The CpG island of CTCFL promoters exhibited demethylation in HCC. DNA methylation occurs mainly in $\mathrm{CpG}$ islands, which are preferentially situated in the 5'UTR of genes overlapping promoters [31]. CTCFL has three promoters, defined as A, B, and C promoters, respectively, corresponding to transcription start sites at $-1447,-899$, and $-658 \mathrm{bp}$ upstream of the first ATG (Figure 1A). In addition, the CpG island of CTCFL that has a high frequency of dinucleotide $\mathrm{CpG}$ sites is located in promoters $\mathrm{B}$ and $\mathrm{C}$ (Figure 1A). We used an interactive database named DiseaseMeth to analyze the methylation value of the $\mathrm{CpG}$ islands in 347 HCC tissues and 50 peritumoral tissues. Interestingly, the CpG island of CTCFL promoters showed significantly lower methylation value in tumor tissues compared with peritumoral tissues (Figure 1B). Therefore, it can be assumed that CTCFL promoters are demethylated in HCC patients.

The methylation status of CTCFL promoters in patients' plasma. We used nested MSP to test the methylation status of CTCFL promoters in HCC, cirrhosis, and 


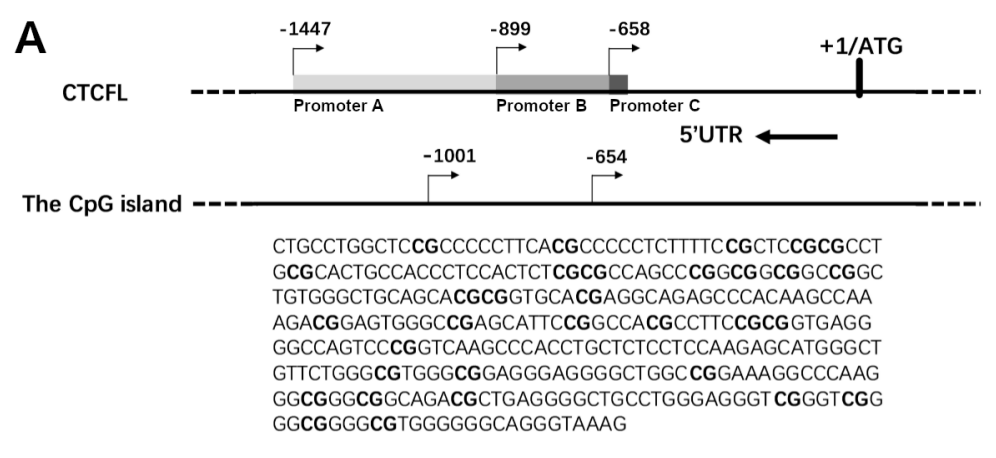

B Methylation of the CpG island in CTCFL promoters

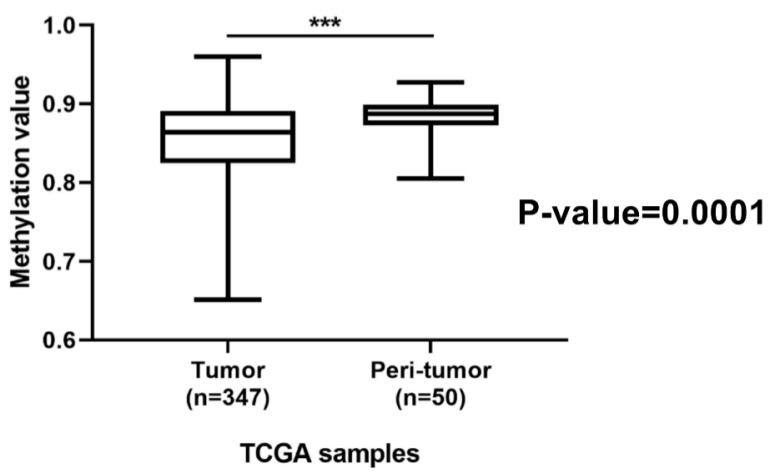

Figure 1. The CpG island of CTCFL promoters exhibited demethylation in HCC. A) A, B, and C promoters of CTCFL correspond to transcription start sites at $-1447,-899$, and -658 bp upstream of the first ATG; the CpG island of CTCFL promoters has a high frequency of dinucleotide CpG sites. B) Methylation value of the CpG island in $347 \mathrm{HCC}$ tissues and 50 peritumoral tissues ( $p=0.0001$ ). $p<0.05$ is considered statistically significant

benign lesion patients' plasma. The sequence amplified by MSP is located in the CpG island of CTCFL promoters (Figure 2A). The methylation status of plasma samples was analyzed by polyacrylamide gel electrophoresis and silver staining (Figure 2B). The results showed that 26 of 43 HCC plasma samples $(60.4 \%)$ and 10 of 19 cirrhosis plasma samples $(52.6 \%)$ were demethylated, while 11 of 14 benign lesion plasma samples (78.6\%) were methylated (Table 1). The hypomethylation of CTCFL promoters in HCC plasma samples was significantly different from that in benign lesion plasma samples $(\mathrm{p}=0.026)$ (Table 1$)$. Besides, unmethylated and methylated products detected by MSP were identified by sequencing (Figure 2C).

Demethylation of CTCFL promoters is a potential biomarker for postoperative recurrence. Statistical methods were used to analyze the relationship between the methylation status of CTCFL promoters and clinicopathological characteristics of HCC patients (Table 2). As shown in the Table 2, the demethylation of CTCFL promoters was negatively correlated with tumor nodules $(\mathrm{p}=0.019)$ and positively correlated with microvascular involvement (MVI) $(\mathrm{p}=0.001)$. It was observed that $36.8 \%$ of CTCFL demethylated plasma samples were from patients with postoperative recurrence, instead, there were no patients with recurrence in CTCFL methylated plasma samples $(\mathrm{p}=0.031)$. Neverthe- less, the methylation status of CTCFL promoters was significantly irrelevant with gender, age, histopathologic grading, cirrhosis, tumor size, metastasis, vessel carcinoma embolus, satellite nodules, invasion of Glisson's capsule, fibrosis grade, HBsAg, and AFP.

Hypomethylation of CTCFL promoters is a potential biomarker for poor prognosis. To determine whether the hypomethylation of CTCFL promoters can be used as a prognostic biomarker, we obtained 347 HCC patients' prognostic information from the TCGA database. KaplanMeier analysis was conducted to investigate the overall survival (OS). According to the mean methylation value of CTCFL promoters' $\mathrm{CpG}$ island, the data were divided into hypermethylated group and hypomethylated group. There were statistically significant differences in overall survival

Table 1. The methylation status of CTCFL promoters in patients' plasma.

\begin{tabular}{lccc}
\hline \multirow{2}{*}{ Group } & \multicolumn{2}{c}{ CTCFL status/n (\%) } & \multirow{2}{*}{ p-value } \\
\cline { 2 - 3 } & Unmethylated & Methylated & \\
\hline HCC $(\mathrm{n}=43)$ & $26(60.5 \%)$ & $17(39.5 \%)$ & \\
Liver cirrhosis $(\mathrm{n}=19)$ & $10(52.6 \%)$ & $9(47.4 \%)$ & $\mathrm{A}=0.564$ \\
Benign lesion $(\mathrm{n}=14)$ & $3(21.4 \%)$ & $11(78.6 \%)$ & $\mathrm{B}=0.026$ \\
\hline
\end{tabular}

A: comparison between HCC and liver cirrhosis; $\mathrm{B}$ : comparison between HCC and benign lesion. $\mathrm{p}<0.05$ is considered statistically significant 
Table 2. Correlation between the methylation status of plasma and clinicopathological characteristics.

\begin{tabular}{|c|c|c|c|}
\hline \multirow{2}{*}{$\begin{array}{l}\text { Clinicopathological } \\
\text { parameters }\end{array}$} & \multicolumn{2}{|c|}{ CTCFL status/n (\%) } & \multirow{2}{*}{ p-value } \\
\hline & Unmethylated & Methylated & \\
\hline \multicolumn{4}{|l|}{ Gender } \\
\hline Male & $17(39.5)$ & $14(32.6)$ & \multirow{2}{*}{0.387} \\
\hline Female & $9(20.9)$ & $3(7.0)$ & \\
\hline \multicolumn{4}{|l|}{ Age (years) } \\
\hline$<55$ & $13(30.2)$ & $9(21.0)$ & \multirow{2}{*}{1.000} \\
\hline$\geq 55$ & $13(30.2)$ & $8(18.6)$ & \\
\hline \multicolumn{4}{|l|}{ Recurrence } \\
\hline Present & $7(16.3)$ & $0(0.0)$ & \multirow{2}{*}{0.031} \\
\hline Absent & $19(44.2)$ & $17(39.5)$ & \\
\hline \multicolumn{4}{|l|}{ Histopathological grading } \\
\hline Moderately and poorly & $15(34.8)$ & $11(25.6)$ & \multirow{2}{*}{0.755} \\
\hline Well & $11(25.6)$ & $6(14.0)$ & \\
\hline \multicolumn{4}{|l|}{ Cirrhosis } \\
\hline With & $15(34.8)$ & $10(23.3)$ & \multirow{2}{*}{1.000} \\
\hline Without & $11(25.6)$ & $7(16.3)$ & \\
\hline \multicolumn{4}{|l|}{ Tumor size $(\mathrm{cm})$} \\
\hline$<5 \mathrm{~cm}$ & $18(41.9)$ & $9(20.9)$ & \multirow{2}{*}{0.343} \\
\hline$\geq 5 \mathrm{~cm}$ & $8(18.6)$ & $8(18.6)$ & \\
\hline \multicolumn{4}{|l|}{ Tumor nodules } \\
\hline Single & $26(60.5)$ & $13(30.2)$ & \multirow{2}{*}{0.019} \\
\hline Multiple & $0(0.0)$ & $4(9.3)$ & \\
\hline \multicolumn{4}{|l|}{ Metastasis } \\
\hline With & $1(2.3)$ & $1(2.3)$ & \multirow{2}{*}{1.000} \\
\hline Without & $25(58.2)$ & $16(37.2)$ & \\
\hline \multicolumn{4}{|l|}{$\begin{array}{l}\text { Vessel carcinoma embolus } \\
\text { and satellite nodules }\end{array}$} \\
\hline With & $3(7.0)$ & $1(2.3)$ & \multirow{2}{*}{0.930} \\
\hline Without & $23(53.5)$ & $16(37.2)$ & \\
\hline \multicolumn{4}{|l|}{ MVI } \\
\hline With & $17(39.5)$ & $2(4.7)$ & \multirow{2}{*}{0.001} \\
\hline Without & $9(20.9)$ & $15(34.9)$ & \\
\hline \multicolumn{4}{|l|}{ Invasion of Glisson's capsule } \\
\hline With & $12(27.9)$ & $9(20.9)$ & \multirow{2}{*}{0.760} \\
\hline Without & $14(32.6)$ & $8(18.6)$ & \\
\hline Fibrosis grade & & & \\
\hline $1-3$ & $10(23.3)$ & $7(16.2)$ & 1000 \\
\hline $4-6$ & $16(37.2)$ & $10(23.3)$ & 1.000 \\
\hline HBsAg & & & \\
\hline+ & $20(46.5)$ & $15(34.8)$ & 0595 \\
\hline - & $6(14.0)$ & $2(4.7)$ & 0.595 \\
\hline $\operatorname{AFP}(\mathrm{ng} / \mathrm{ml})$ & & & \\
\hline$<25$ & $9(20.9)$ & $9(20.9)$ & \\
\hline$\geq 25$ & $17(39.5)$ & $8(18.6)$ & 0.344 \\
\hline
\end{tabular}

MVI: Microvascular involvement; HBsAg: Hepatitis B surface antigen; AFP: $\alpha$-fetoprotein. $p<0.05$ is considered statistically significant

between the two groups $(p=0.0056)$ and the hypomethylated group showed a worse prognosis (Figure 3A). Moreover, 347 samples were divided into two groups according to the quartile of methylation level, and the hypomethylated group had significantly worse overall survival than the hyper- methylated group $(\mathrm{p}=0.0038)$ (Figure $3 \mathrm{~B})$. As a result, the hypomethylation of CTCFL promoters may be a biomarker for poor prognosis.

\section{Discussion}

Hepatocellular carcinoma (HCC) is one of the most common malignancies with high morbidity, high mortality, and poor prognosis [32]. Until now, biopsies have been one of the gold standards for clinical decision-making [33]. However, because of the invasive characteristic of tumor biopsies, it is difficult to dynamically monitor tumor development [34]. Therefore, as a noninvasive method, liquid biopsies can provide important prognostic information for patients with HCC.

As is known to all, aberrations in DNA methylation are hallmarks of human cancers, including hypomethylation of oncogenes and hypermethylation of tumor suppressor genes [35]. On the one hand, abnormal hypermethylation of tumor suppressor genes in circulating DNA can predict HCC development and serve as a noninvasive biomarker for the prognosis of HCC patients with partial resection [36, 37]. On the other hand, hypomethylation of oncogenes in liquid biopsies is mainly used for early noninvasive detection of the tumor, such as pancreatic ductal adenocarcinoma (PDAC) and bladder cancer [38, 39]. Nonetheless, few studies have identified hypomethylation of oncogenes in cfDNA as a biomarker for tumor prognosis and recurrence.

Previous studies in our laboratory have found that CTCFL is an oncogene with high expression in liver cancer tissues and cells, which is closely related to invasion and recurrence $[21,40]$. And hypomethylation of CTCFL promoters in HCC tissues is strongly associated with patients' clinical stage and prognosis [28]. So far, the methylation status of CTCFL promoters in cfDNA of tumor patients has not yet been reported. Here, we first investigated the methylation status of CTCFL promoters in $43 \mathrm{HCC}, 19$ liver cirrhosis, and 14 benign lesion plasma samples. Our study demonstrated that the CpG island of CTCFL promoters was demethylated in $60.5 \%(26 / 43)$ of HCC patients, but only in $21.4 \%(3 / 14)$ of benign lesion patients $(\mathrm{p}=0.026)$. Unexpectedly, there was no statistical difference in hypomethylation rates between HCC samples and cirrhosis samples $(\mathrm{p}=0.564)$. Considering that the expression of CTCFL in HCC tissues is significantly higher than that in cirrhosis tissues $(p<0.0001)[41]$, we speculate this paradox may be due to the small sample size and complex molecular mechanisms. Among various prognostic factors, the presence of microvascular invasion (MVI) is increasingly considered as a reflection of enhanced local invasion abilities of HCC [42]. Our data showed that the hypomethylation of CTCFL promoters was significantly correlated with microvascular involvement (MVI) $(\mathrm{p}=0.001)$, suggesting that CTCFL demethylation may be involved in tumor invasion. Furthermore, in HCC patients, 36.8\% of CTCFL demethylated group were from patients with postop- 

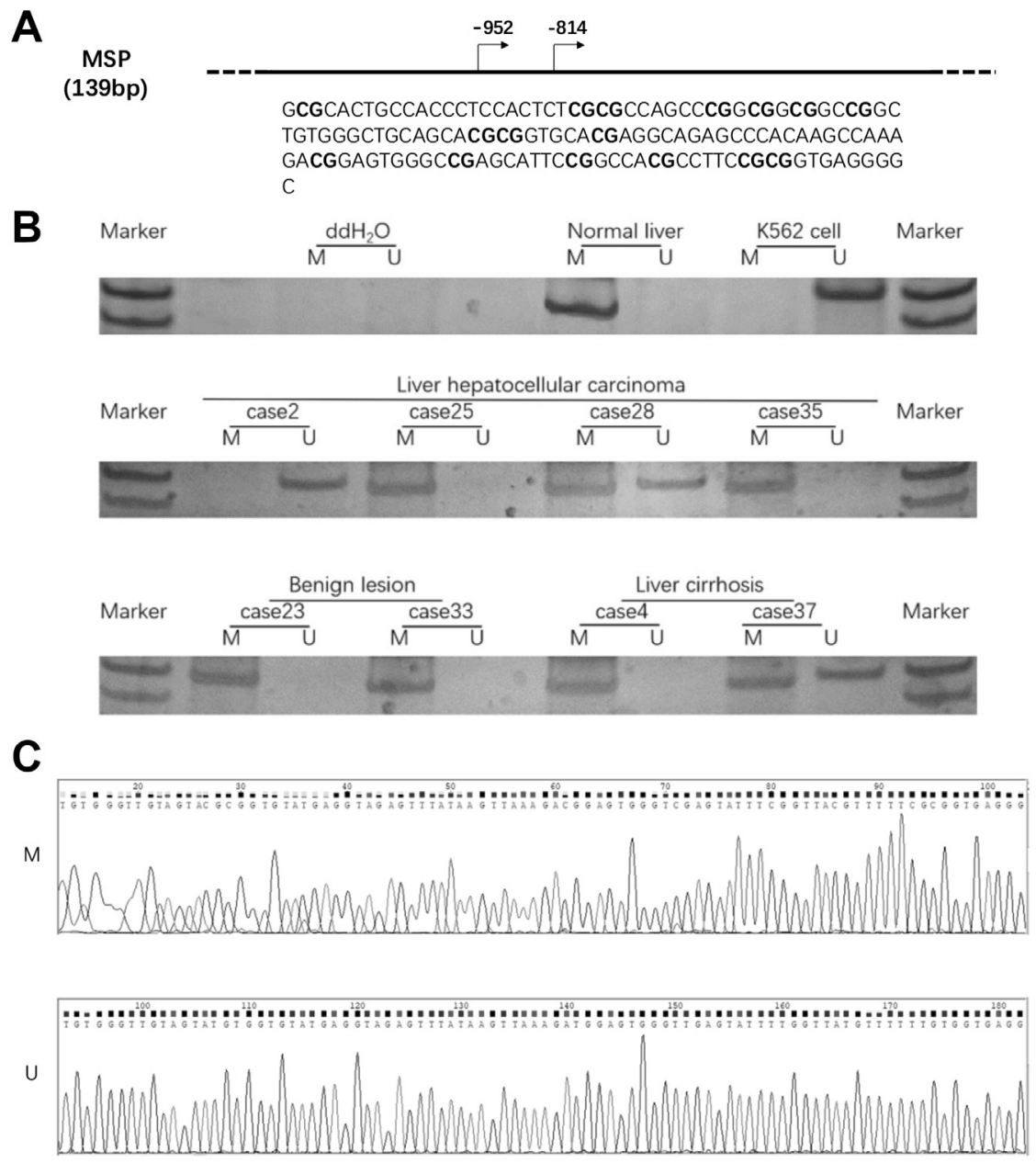

Figure 2. The methylation status of CTCFL promoters in HCC patients' plasma. A) The sequence detected by MSP is $139 \mathrm{bp}$. B) The methylation status of samples was shown by polyacrylamide gel electrophoresis and silver staining, $\mathrm{ddH}_{2} \mathrm{O}$ is blank control, normal liver tissue is a negative control, $\mathrm{K} 562$ cells are positive control. $C$ ) Sequencing results of unmethylated and methylated products detected by MSP. M = Methylated, $U=U n m e t h y l a t e d$.

A

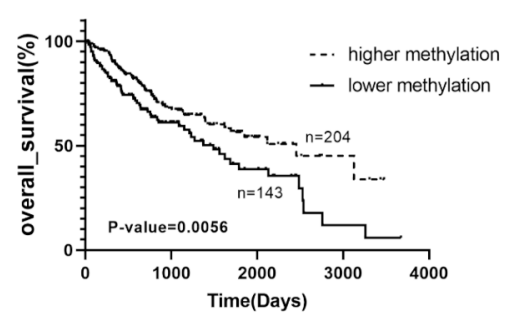

B

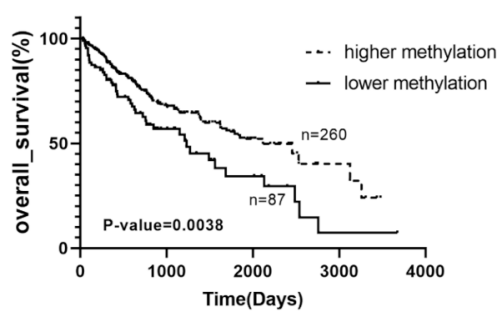

Figure 3. Hypomethylation of CTCFL a potential biomarker for poor prognosis. A) According to the mean methylation value of CTCFL promoters' CpG island, the 347 data were divided into hypermethylated group and hypomethylated group $(\mathrm{p}=0.0056)$. B) According to the quartile of methylation level, the 347 data were divided into hypermethylated group and hypomethylated group ( $p=0.0038)$. Kaplan-Meier analyses were conducted to investigate overall survival (OS). $p<0.05$ is considered statistically significant

erative recurrence, while the methylated group had no recurrence $(\mathrm{p}=0.031)$. Consistent with this, clinical prognosis data from the TCGA database indicated that HCC patients with CTCFL demethylation showed worse prognosis than those with methylation $(p=0.0056)$. Since all plasma samples were obtained from the West China Hospital of Sichuan University only two months ago, we were unable to get patients' prognosis information. Therefore, we tentatively put forward that the hypomethylation of CTCFL promoters could be used to predict the malignant degree and poor prognosis of HCC. 
In conclusion, we provide evidence that the $\mathrm{CpG}$ islands of CTCFL promoters are largely demethylated in HCC patients' plasma. The methylation status of CTCFL promoters in cellfree DNA may be an effective biomarker for monitoring postoperative recurrence in patients with HCC. Hypomethylation of CTCFL promoters could be used as a noninvasive biomarker to predict poor prognosis of HCC. Of course, the small sample size is a deficiency of our study. In a future study, the sample size should be expanded and patients should be followed up to provide powerful evidence for the view that the methylation status of CTCFL promoters could be a molecular marker of liquid biopsies in hepatocellular carcinoma.

Acknowledgments: This research was supported by a grant from the National Natural Science Foundation of China (grant number 81172372).

\section{References}

[1] BERTUCCIO P, TURATI F, CARIOLI G, RODRIGUEZ T, LA VECCHIA $C$ et al. Global trends and predictions in hepatocellular carcinoma mortality. J Hepatol 2017; 67: 302309. https://doi.org/10.1016/j.jhep.2017.03.011

[2] ALLY A, BALASUNDARAM M, CARLSEN R, CHUAH E, CLARKE A et al. Comprehensive and Integrative Genomic Characterization of Hepatocellular Carcinoma. Cell 2017; 169: 1327-1341. https://doi.org/10.1016/j.cell.2017.05.046

[3] BEVANT K, COULOUARN C. Landscape of genomic alterations in hepatocellular carcinoma: current knowledge and perspectives for targeted therapies. Hepatobiliary Surg Nutr 2017; 6: 404-407. https://doi.org/10.21037/hbsn.2017.10.02

[4] DHANASEKARAN R, BANDOH S, ROBERTS L. Molecular pathogenesis of hepatocellular carcinoma and impact of therapeutic advances. F1000Res 2016; 5: F1000 Faculty Rev879. https://doi.org/10.12688/f1000research.6946.1

[5] FORNER A, REIG M, BRUIX J. Hepatocellular carcinoma. Lancet 2018; 391: 1301-1314. https://doi.org/10.1016/ S0140-6736(18)30010-2

[6] OKAJIMA W, KOMATSU S, ICHIKAWA D, MIYAMAE M, OHASHI T et al. Liquid biopsy in patients with hepatocellular carcinoma: Circulating tumor cells and cell-free nucleic acids. World J Gastroenterol 2017; 23: 5650-5668. https:// doi.org/10.3748/wjg.v23.i31.5650

[7] LEON SA, SHAPIRO B, SKLAROFF DM, YAROS MJ. Free DNA in the Serum of Cancer Patients and the Effect of Therapy. Cancer Res 1977; 37: 646-650.

[8] JIANG P, CHAN KCA, LO YMD. Liver-derived cell-free nucleic acids in plasma: Biology and applications in liquid biopsies. J Hepatol 2019; 71: 409-421. https://doi.org/10.1016/j. jhep.2019.04.003

[9] SCHWARZENBACH H, HOON DSB, PANTEL K. Cell-free nucleic acids as biomarkers in cancer patients. Nat Rev Cancer 2011; 11: 426-437. https://doi.org/10.1038/nrc3066

[10] WEDGE E, HANSEN JW, GARDE C, ASMAR F, THOLSTRUP D et al. Global hypomethylation is an independent prognostic factor in diffuse large B cell lymphoma. Am J Hematol 2017; 92: 689-694. https://doi.org/10.1002/ajh.24751
[11] MUDBHARY R, HOSHIDA Y, CHERNYAVSKAYA Y, JACOB V, VILLANUEVAA et al. UHRF1 overexpression drives DNA hypomethylation and hepatocellular carcinoma. Cancer Cell 2014; 25: 196-209. https://doi.org/10.1016/j. ccr.2014.01.003

[12] VAN TONGELEN A, LORIOT A, DE SMET C. Oncogenic roles of DNA hypomethylation through the activation of cancer-germline genes. Cancer Lett 2017; 396: 130-137. https://doi.org/10.1016/j.canlet.2017.03.029

[13] LOUKINOV DI, PUGACHEVA E, VATOLIN S, PACK SD, MOON $\mathrm{H}$ et al. BORIS, a novel male germ-line-specific protein associated with epigenetic reprogramming events, shares the same 11-zinc-finger domain with CTCF, the insulator protein involved in reading imprinting marks in the soma. Proc Natl Acad Sci U S A 2002; 99: 6806-6811. https:// doi.org/10.1073/pnas.092123699

[14] KALEJS M, ERENPREISA J. Cancer/testis antigens and gametogenesis: a review and "brain-storming" session. Cancer Cell Int 2005; 5: 4. https://doi.org/10.1186/1475-2867-5-4

[15] RISINGER JI, CHANDRAMOULI GV, MAXWELL GL, CUSTER M, PACK S et al. Global expression analysis of cancer/testis genes in uterine cancers reveals a high incidence of BORIS expression. Clin Cancer Res 2007; 13: 1713-1719. https://doi.org/10.1158/1078-0432.CCR-05-2569

[16] TIFFEN JC, BAILEY CG, MARSHALL AD, METIERRE C, FENG $Y$ et al. The cancer-testis antigen BORIS phenocopies the tumor suppressor CTCF in normal and neoplastic cells. Int J Cancer 2013; 133: 1603-1613. https://doi.org/10.1002/ ijc. 28184

[17] HONG JA, KANG Y, ABDULLAEV Z, FLANAGAN PT, PACK SD et al. Reciprocal binding of CTCF and BORIS to the NY-ESO-1 promoter coincides with derepression of this cancer-testis gene in lung cancer cells. Cancer Res 2005; 65: 7763-7774. https://doi.org/10.1158/0008-5472.CAN-050823

[18] VELAZQUEZ-HERNANDEZ N, REYES-ROMERO MA, BARRAGAN-HERNANDEZ M, GUERRERO-ROMERO F, RODRIGUEZ-MORAN $\mathrm{M}$ et al. BORIS and CTCF are overexpressed in squamous intraepithelial lesions and cervical cancer. Genet Mol Res 2015; 14: 6094-6100. https://doi. org/10.4238/2015.June.8.7

[19] CHEEMA Z, HARI-GUPTA Y, KITA GX, FARRAR D, SEDDON I et al. Expression of the cancer-testis antigen BORIS correlates with prostate cancer. Prostate 2014; 74: 164-176. https://doi.org/10.1002/pros.22738

[20] SCANLAN MJ, SIMPSON AJ, OLD LJ. The cancer/testis genes: review, standardization, and commentary. Cancer Immun 2004; 4: 1 .

[21] LIU Q, CHEN K, LIU Z, HUANG Y, ZHAO R et al. BORIS up-regulates OCT4 via histone methylation to promote cancer stem cell-like properties in human liver cancer cells. Cancer Lett 2017; 403: 165-174. https://doi.org/10.1016/j. canlet.2017.06.017

[22] RENAUD S, LOUKINOV D, ALBERTI L, VOSTROV A, KWON YW et al. BORIS/CTCFL-mediated transcriptional regulation of the hTERT telomerase gene in testicular and ovarian tumor cells. Nucleic Acids Res 2011; 39: 862-873. https://doi.org/10.1093/nar/gkq827 
[23] KOSAKA-SUZUKI N, SUZUKI T, PUGACHEVA EM, VOSTROV AA, MORSE HC, 3RD et al. Transcription factor BORIS (Brother of the Regulator of Imprinted Sites) directly induces expression of a cancer-testis antigen, TSP50, through regulated binding of BORIS to the promoter. J Biol Chem 2011; 286: 27378-27388. https://doi.org/10.1074/jbc. M111.243576

[24] ZAMPIERI M, CICCARONE F, PALERMO R, CIALFI S, PASSANANTI $\mathrm{C}$ et al. The epigenetic factor BORIS/CTCFL regulates the NOTCH3 gene expression in cancer cells. Biochim Biophys Acta 2014; 1839: 813-825. https://doi. org/10.1016/j.bbagrm.2014.06.017

[25] HOFFMANN MJ, MULLER M, ENGERS R, SCHULZ WA. Epigenetic control of CTCFL/BORIS and OCT4 expression in urogenital malignancies. Biochem Pharmacol 2006; 72: 1577-1588. https://doi.org/10.1016/j.bcp.2006.06.020

[26] RENAUD S, PUGACHEVA EM, DELGADO MD, BRAUNSCHWEIG R, ABDULLAEV $\mathrm{Z}$ et al. Expression of the CTCF-paralogous cancer-testis gene, brother of the regulator of imprinted sites (BORIS), is regulated by three alternative promoters modulated by CpG methylation and by CTCF and p53 transcription factors. Nucleic Acids Res 2007; 35: 7372-7388. https://doi.org/10.1093/nar/gkm896

[27] HOIVIK EA, KUSONMANO K, HALLE MK, BERG A, WIK E et al. Hypomethylation of the CTCFL/BORIS promoter and aberrant expression during endometrial cancer progression suggests a role as an Epi-driver gene. Oncotarget 2014; 5: 1052-1061. https://doi.org/10.18632/oncotarget.1697

[28] HE J, HUANG Y, LIU Z, ZHAO R, LIU Q et al. Hypomethylation of BORIS is a promising prognostic biomarker in hepatocellular carcinoma. Gene 2017; 629: 29-34. https://doi. org/10.1016/j.gene.2017.07.077

[29] YOON SL, ROH YG, LEE SH, KIM SH, KIM MC et al. Analysis of promoter methylation and polymorphic minisatellites of BORIS and lack of association with gastric cancer. DNA Cell Biol 2011; 30: 691-698. https://doi.org/10.1089/ dna.2011.1248

[30] XIONG Y, WEI Y, GU Y, ZHANG S, LYU J et al. DiseaseMeth version 2.0: a major expansion and update of the human disease methylation database. Nucleic Acids Res 2017; 45: D888-D895. https://doi.org/10.1093/nar/gkw1123

[31] GARDINER-GARDEN M, FROMMER M. CpG islands in vertebrate genomes. J Mol Biol 1987; 196: 261-282. https:// doi.org/10.1016/0022-2836(87)90689-9

[32] YIN CQ, YUAN CH, QU Z, GUAN Q, CHEN H et al. Liquid Biopsy of Hepatocellular Carcinoma: Circulating TumorDerived Biomarkers. Dis Markers 2016; 2016: 1427849. https://doi.org/10.1155/2016/1427849
[33] KUBACZKOVA V, VRABEL D, SEDLARIKOVA L, BESSE L, SEVCIKOVA S. Cell-free DNA - Minimally invasive marker of hematological malignancies. Eur J Haematol 2017; 99: 291-299. https://doi.org/10.1111/ejh.12925

[34] WU Z, YANG Z, DAI Y, ZHU Q, CHEN LA. Update on liquid biopsy in clinical management of non-small cell lung cancer. Onco Targets Ther 2019; 12: 5097-5109. https://doi. org/10.2147/OTT.S203070

[35] LIANG G, WEISENBERGER DJ. DNA methylation aberrancies as a guide for surveillance and treatment of human cancers. Epigenetics 2017; 12: 416-432. https://doi.org/10.1 080/15592294.2017.1311434

[36] HUANG Y, WEI L, ZHAO RC, LIANG WB, ZHANG J et al. Predicting hepatocellular carcinoma development for cirrhosis patients via methylation detection of heparocarcinogenesis-related genes. Journal of Cancer 2018; 9(12): 22032210.

[37] WEI L, HUANG Y, ZHAO R, ZHANG J, LIU Q et al. Detection of promoter methylation status of suppressor of cytokine signaling 3 (SOCS3) in tissue and plasma from Chinese patients with different hepatic diseases. Clin Exp Med 2018; 18: 79-87. https://doi.org/10.1007/s10238-017-0473-2

[38] CHENG THT, JIANG P, TEOH JYC, HEUNG MMS, TAM JCW et al. Noninvasive Detection of Bladder Cancer by Shallow-Depth Genome-Wide Bisulfite Sequencing of Urinary Cell-Free DNA for Methylation and Copy Number Profiling. Clin Chem 2019; 65: 927-936. https://doi.org/10.1373/ clinchem.2018.301341

[39] MARDIN WA, NTALOS D, MEES ST, SPIEKER T, SENNINGER $\mathrm{N}$ et al. SERPINB5 Promoter Hypomethylation Differentiates Pancreatic Ductal Adenocarcinoma From Pancreatitis. Pancreas 2016; 45: 743-747. https://doi. org/10.1097/MPA.0000000000000526

[40] CHEN K, HUANG W, HUANG B, WEI Y, LI B et al. BORIS, brother of the regulator of imprinted sites, is aberrantly expressed in hepatocellular carcinoma. Genet Test Mol Biomarkers 2013; 17: 160-165. https://doi.org/10.1089/ gtmb.2012.0242

[41] ZHAO R, CHEN K, ZHOU J, HE J, LIU J et al. The prognostic role of BORIS and SOCS3 in human hepatocellular carcinoma. Medicine (Baltimore) 2017; 96: e6420. https:// doi.org/10.1097/MD.0000000000006420

[42] ZHANG X, LI J, SHEN F, LAU WY. Significance of presence of microvascular invasion in specimens obtained after surgical treatment of hepatocellular carcinoma. J Gastroenterol Hepatol 2018; 33: 347-354. https://doi.org/10.1111/ jgh.13843 